\title{
Biological Agents in the Treatment of Rheumatoid Arthritis
}

\author{
SM KAMAL ${ }^{\mathrm{a}}$, MA BAKAR ${ }^{\mathrm{b}}$
}

\begin{abstract}
Summary:
Rheumatoid arthritis (RA) is the commonest joint disease with considerable morbidity and mortality. Conventional disease modifying antirheumatic drugs like methotrexate form the cornerstone of therapy. These drugs have several limitations in terms of slow onset of action, adverse effects and modest remission rates. Several cytokines are involved in the pathogenesis of RA. Biological agents that specifically inhibit the effects of tumour necrosis factor-alpha (TNF-a) or interleukin-1 (IL-1) represent a major advancement in the treatment of RA. By targeting mediators that are directly involved in the pathogenesis of RA, these agents slow the
\end{abstract}

\section{Introduction:}

Rheumatoid arthritis is a chronic inflammatory disease. Established treatment is limited because of the unsatisfactory clinical response or the development of unexpected adverse events with the drugs used. In recent years intensive research into the pathogenesis of RA has yielded information which permits clear insights into the mechanism of the underlying disease. Inflammatory cells produce a number of cytokines, which play a role in inflammation leading to damage to the bone and cartilage. These findings finally led to the development of biological agents for the treatment of rheumatoid arthritis. These agents target cytokines such as tumour necrosis factor-alpha (TNF-a), interleukin-1 (IL-1), interleukin-6 (IL-6) or cell surface molecules such as (CD4, CD5, CD7, IL-2 receptor, CDw52 or CD54). New biological agents evaluated for treatment of RA have shown much success in different clinical trails ${ }^{1}$. RA is no longer considered a benign disease. Statistical

a. Dr. S M Kamal, FCPS, Associate Professor, Department of Medicine, Khulna Medical College, Khulna.

b. Prof. Md. Abu Bakar, FCPS, FRCP, Professor, Department of Medicine, Khulna Medical College, Khulna.

Address of Correspondence: S M Kamal, FCPS, Associate Professor, Department of Medicine, Khulna Medical College, Khulna. Received: 10 April, 2010

Accepted: 8 November, 2010 radiological progression of bone and cartilage damage in joints, prevent or delay the onset of disability.

These are highly specific and better tolerated. The use of these biological agents needs careful monitoring for side effects, including the development of infection. Additional anti-cytokine agents for the treatment of RA are under further development.

Key words: Rheumatoid arthritis, biological agents, inflammatory cytokine.

(J Bangladesh Coll Phys Surg 2011; 29: 27-31)

analysis has shown increased mortality in patients with RA compared with average population ${ }^{2}$.

Biological agents are recommended for the treatment of rheumatoid arthritis, juvenile chronic arthritis, still's disease, ankylosing spondylitis, psoriasis, psoriatic arthritis, castleman's disease, B-cell lymphoma, crohn's disease, vasculitis (refractory wegener's granulomatosis, life threatening Behcets disease) ${ }^{3}$.

This review article will give a short overview on the various biological agents recommended in the therapy of rheumatoid arthritis (RA).

\section{Pathogenesis of Rheumatoid Arthritis}

Rheumatoid arthritis (RA) is characterised by persistent inflammatory synovitis. It predominantly affects the peripheral joints. Exact aetiology of RA is not known. Different research works suggest that RA is caused by an unidentified arthritogenic antgen ${ }^{4}$. The antigen could be either exogenous such as viral or bacterial protein or endogenous such as human cartilage glycoprotein 39 or heavy chain-binding protein ${ }^{5}$.

Antigen-activated CD4+ T-cells stimulate monocytes, macrophages and synovial fibroblasts to produce various cytokines. Tumour necrosis factor - alpha (TNF-a), interleukin -1 (IL-1) and interleukin-6 (IL-6) are the key cytokines that drive inflammation in RA and cause 
joint damage. They are potent stimulators of synovial fibroblasts, osteoclasts and chondrocytes that release tissue destroying matrix metalloproteinases (MMP), which centribule to joint damage ${ }^{6}$.

Activated CD4+ T-cells also stimulate B cells to produce immunoglobulins including rheumatoid factor (RF). RF may involve the activation of complement through the formation of immune complex. The products of activated macrophages, lymphocytes and fibroblasts stimulate angiogenesis ${ }^{7}$. Inflammatory cells are recruited into the joint by expression of adhesion molecules in endothelial cells in the synovium. This leads to the formation of hyperplastic, proliferating, inflammed synovium also called "Pannus"7. Activated macrophages and synovial fibroblasts are present in the interface between the Pannus and cartilage causing damage to the joint ${ }^{8}$. There occurs progressive erosion of subchondral bone with Juxta-articular osteopenia. Destruction of bone and cartilage occurs progressively leading to significant disability ${ }^{9}$.

Radiological evidence of substantial joint damage is seen within 2 years of disease onset. Evidence of bone erosion is seen within first-few months by magnetic resonance imaging (MRI). Osteoporosis due to reduced bone mineral density increases the risk of bone fracture $^{11-12}$. Recent study have shown that $80 \%$ of patients with RA are disabled within 10 years and survival is reduced ${ }^{13}$.

\section{Indications and clinical considerations of biological agents}

Biological agents are used in the management of Rheumatoid Arthritis (RA). Juvenile idiopathic arthritis (JIA), still's disease, ankylosing spondylitis, psoriasis, Psoriatic arthritis, crohn's disease, vasculitis (Refractory wegener's granulomatosis and Behcet's disease).

The onset of action is rapid and occurs within 2 to 4 weeks. Infliximab can not be used as monotherapy and has to be combined with methotrexate. Other agents can be used alone or in combination with methotrexate ${ }^{14,15}$. Cytokine antagonists should be withdrawn in the face of adverse events or lack of adequate response. If one TNF-a blocker fails, substitution with another agent may be helpful ${ }^{16}$. Cardiovascular disease is the major cause of increased mortality in RA due to accelerated atherosclerosis ${ }^{17,18}$. Cytokine antagonists have shown a favourable response in endothelial cell dysfunction in these patients ${ }^{19}$.
Classification and mode of action of biological agents

Functionally biological agents can be divided into three classes.

1. Interfere cytokine function

2. Inhibit the second signal required for T-cell activation so called co-stimulation blockade

3. B cell depletion.

Infliximab, etanercept, adalimumab and the interleukin1 (IL-1) receptor antagonist anakinra were the first generation of biologics approved in the treatment of RA. Abatacept, rituximab and tocilizumab represent the next generation of biologics in $\mathrm{RA}^{22}$.

1. Interfere cytokine function

The anti-cytokine approaches include

a) Anti-tumour necrosis factor-alpha (AntiTNF- $\alpha$ )

Infliximab, Etanerecpt, Adalimumab

b) Anti-interleukin-1 (Anti-IL-1)

Anakinra

c) Anti-interleukin-6 (Anti-IL-6)

Tocilizumab

There are three types of anti-cytokine molecules:

i) Soluble receptor antagonist - Etanercept

ii) Monoclonal antibodies (mAb) to cytokines or to their receptors

Infliximab, Adalimumab, certalizumab

iii) Cell surface receptor antagonist protein: Anakinra, Tocilizumab.

2. Inhibit the "Second signal" required for T-cell activation, the co-stimulation blocker, Abatacept.

3. B cell depletion - Rituximab $20,21,22$.

Dosage, administration, side effects and contraindications of a few biological agents used in the treatment of rheumatoid arthritis

Infliximab (remicade)

$3 \mathrm{mg} / \mathrm{kg}$ i.v infusion at weeks 0,2 and 6 followed by maintenance dose every 8 weeks. Has to be combined with methotrexate.

Side effects - Infusion reaction (Fever, chills, urticaria, chest pain, dyspnoea, hypotension), antibody formation, 
infection, upper respiratory infection, reactivation of tuberculosis (TB), exacerbation of demyelinating disease,

contraindications - Active infection, uncontrolled diabetes mellitus, surgery (withhold for 2 weeks postoperatively) $)^{23,24,25}$.

\section{Etanercept (enbrel)}

$25 \mathrm{mg}$ subcutaneonsly twice a week or 50mg once a week. May be given with MTX or as monotherapy.

Side effects - Injection site reactions, upper respiratory infection, development of anti-nuclear antibody (ANA), infection, reactivation of $\mathrm{TB}$, exacerbation of demyelinating disease.

Contraindications - Active infection, uncontrolled DM, Surgery (withhold for 2 weeks post operatively) ${ }^{26,27}$.

\section{Adalimumab (humira)}

$40 \mathrm{mg}$ subcutaneously every 2 weeks. May be given with MTX or as monotherapy.

Side effects - upper respiratory infection, injection site pain, rash, headache, sinusitis, infection, exacerbation of demyclinating disease.

Contraindications - Active infection ${ }^{26,27}$.

\section{Anakinra (kinaret)}

$100 \mathrm{mg}$ subcutaneously once daily. May be given with MTX or as monotherapy.

Side effects - Injection site reaction, infection, neutropenia.

Contraindications - active infection ${ }^{28}$.

\section{Tocilizumab}

$8 \mathrm{gm} / \mathrm{kg}$ subcutaneously every four weeks ${ }^{29}$.

Safety Issues in Biological Agent Therapy

The cytokines play an important role in protective immunity. The risk of infection increases with the use of anti-cytokines ${ }^{30}$. Reactivation of tuberculosis occurs mostly with infliximab. Opportunistic infection and lymphoma has been reported with the use of TNF-a antagonists ${ }^{31,32}$. Demyelinating disorders may occur by therapy with all biological agents except anakinra ${ }^{33}$. Injection site reaction can occur ${ }^{34}$. Rarely bone marrow aplasia have been reported. Increased severity of heart failure, hepatotoxicity and drug induced lupus can occur. The side effects are mild, self limiting and seldom enough to warrant discontnuation of biologics. Severe adverse events are rare. Proper patient selection and preventive measures may limit the risks further ${ }^{35}$.

\section{Pre-Treatment Consideration in Biological Agent Therapy}

Existance of any contraindications to the use of biological agents needs to be considered before commencement of therapy. Absolute contraindications for the use of TNF-a blockers are active infections (Including infected prosthesis, severe sepsis), recurrent or chronic infections (such as branchiectasis, untreated tuberculosis), moderate to severe congestive cardiac failure, Multiple sclerosis, optic neuritis, combined treatment with anakinra (IL-1 receptor antagonist). Active or recent history of malignancy except skin cancer. Relative contraindications are pregnancy, lactation, HIV, HBV and HCV infection ${ }^{36}$.

\section{Monitoring during therapy with biologics}

Clinicians should be aware of potential treatment related adverse effects and monitor the patient accordingly. Most important adverse effects of anti TNF-a therapy is increased risk of severe infections due to blockade of pro-inflammatory cytokines. The half life of biological agents become relevant. Adalimumab has long half life of 2 weeks and produce a longer period of immunosuppresion with risk of infection per dose. Care should be taken for diabetic patients. Cutaneous injection site reaction consists of local erythema and swelling which usually subsides within 24 hours. It can be lessened by predosing with antihistamine. Intravenous infusion reactions are fever, chills and nausea. These can also be prevented by premedication ${ }^{37}$. Impact of biological agents in current clinical practice Biological response modifiers represent advancement in the treatment of RA. Disease activity can be well controlled and joint function improves almost to normal. There are still some non-responders and newer agents address some of these needs ${ }^{38}$.

\section{Future trends of biological agents}

Anti- TNF-a preparations that are given as monthly subcutaneous injections are currently being developed ${ }^{38}$.

\section{Conclusions:}

The availability of biological agents that target specific cytokines involved in the joint destruction will raise the 
new era in the treatment of RA. The major hindrance to the use of cytokine antagonists is their cost. Epidemiological studies will be needed to document the long term benefits and risks associated with the cytokines.

\section{References:}

1. Lorenz HM, Kalden JR. Biological agents in Rheumatoid arthritis. Biodrugs 1998; 9: 303-329.

2. Harris ED. Rheumatoid arthrtis: Pathophysiology and implications for therapy. N Engl J Med 1990; 322: 1277-83.

3. Shankar S, Handa R. Biological agents in rheumatoid arthritis. J Postgrad Med 2004; 50: 293-299.

4. Gregersen PK, Silver J, Winchester RJ. The shared epitope hypothesis: an approach to understanding the molecular genetics of susceptibility to rheumatoid arthritis. Arthritis Rheum 1987; 30: 1205-13.

5. Blass S, Engel JM, Burmester GR. The immunologic homunculus in rheumatoid arthritis. Arthritis Rheum 1999; 42: 2499-506

6. Shingu M, Nagai Y. Isayama T. Naono T, Nobunaga M. The effects of cytokines on metalloproleinase inhibitors (TIMP) and collagenase production by human chondrocytes and TIMP Production by synovial cells and endothelial cells. Clin Exp Immunol 1993; 94:145-9.

7. Choy EH, Panayi GS. Cytokine pathways and joint inflammation in rheumatoid arthritis. N Engl J Med 2001; 344: 907-16.

8. Kong YY, Feige U, Sarosi I, Balon B, Tafuri A, Morony S et al. Activated $\mathrm{T}$ cells regulate bone loss and joint destruction in adjuvant arthritis through osteoprotegerin ligand. Nature 1999; 402: 304-9.

9. Pincus T. Long-term outcomes in rheumatoid arthritis. $\mathrm{Br} \mathrm{J}$ Rheumatol 1995; 34: 59-73.

10. Scott DL, Pugner K, Kaarela K et al. The links between joint damage and disability in rheumatoid arthritis. Rheumatology 2000; 39: 122-32.

11. Abramson SB, Amin A. Blocking the effects of IL-1 in rheumatoid arthritis protects bone and cartilage. Rheumatology 2002; 41: 972-980.

12. Klarlund M, Ostergaard M, Jensen KE, Madsen JL, Skjodt H, Lorenzen L. Magnetic resonance imaging, radiography and scintigraphy of the finger joints: one year follow up of patients with early arthritis. A Population based study. Arthritis Rheum 1984; 27: 1353-61.

13. Young A, Koduri G, Batley M, Kulinskaya E, Gough A, Norton $\mathrm{S}$ et al. Mortality in rheumatoid arthritis. Increased in the early course of disease, in ischaemic heart disease and in pulmonary fibross. Rheumatology 2007; 46: 350-7.

14. Emery P, Reginster JY, Appelboom T, Breedveld FC, Edelmann E, Kekow J, et al. WHO collaborating centre consensus meeting on anticytokine therapy in rheumatoid arthritis. Rheumotology 2001; 4: 699-702.

15. Kremer JM, Rational use of new and existing disease modifying agents in rheumatoid arthritis. Ann intern Med 2001; 134: 695-706.

16. Hansen KE, Hildebrand JR, Genovese MC, Cush JJ, Patel S, Cooley DA, et al. The efficacy of switching from etanercept to infliximab in patients with rheumatoid arthritis. J Rheumatol 2004; 31: 10098-102.

17. Hurlimann D, Forster A, Nall G, Enseleit F, Chenevard F, Distler O, et al. Anti-Tumor Necrosis factor treatment improves endothelial function in patients wth rheumatoid arthritis. Circulation 2002; 106: 2184-7.

18. Choi HK, Hernam MA, Seeger JD, Robins JM, Wolfe F. Methotrexate and mortality in patients with rheumatoid arthritis: a prospective study. Lancet 2002; 359: 1173-7

19. Gonzalez- Juanatey C, Testa A, Garcia- castelo A, Garcia Porrua C, Liorea J, Gonzalez - Gay MA. Active but transient improvement of endothelial function in rheumatoid arthritis patients undergoing long term treatment with anti-tumor necrosis factor-a antibody. Arthritis Rheum 2004; 51: 44750 .

20. Lee CS. The biological agents: The Holy Grait for rheumatic disease? J Rheumatol 2007; 21: 1-5.

21. Genovese MC, Becker JC, Schiff M, et al. Abatacept for rheumatoid arthritis refractory to tumor necrosis factor alpha inhibition. N Engl J Med 2005, 353: 1114-23.

22. Edwards Je, Szezepanski L, Szechinski J et al. Efficacy of B cell targeted therapy with rituximab in patients wth rheumatoid arthritis. N Engl J Med 2004; 350: 2572-81.

23. Nash PT, Florin TH, Tumor necrosis factor inhibitors. Med J Aust 2005; 183: 205-8.

24. Schreiber S, Khaliq-Kareemi M, Lawrance IC, et al. Maintenance therapy with certolizumab pegol for crohn's disease. N Engl J Med 2007; 357: 239-50.

25. Bochncke WH, Prinz J, Gottlieb AB. Biologic therapies for psoriasis. J Rheumatol 2006; 33: 1439-41.

26. Furst DE, Breedveld FC, Kalden JR, et al. Updated consensus statement on biological agents, specifically tumour necrosis factor alpha (TNF-a) blocking agents and interleukin-1 receptor antagonist (IL-1ra), for the treatment of rheumatic diseases. Ann Rheum Dis 2005; 64: 2-14.

27. Haraoui B, Differentiating the efficacy of the tumor necrosis factor inhibitors. Semin Arthritis Rheum 2005; 34: 7-11.

28. Bresniham B, Alvaro-Gracia JM, Cobby M et al. Treatment of rheumatoid arthritis with recombinant human interleukin1 receptor antagonist. Arthritis Rheum 1998; 41: 2196-204.

29. Smolen JS, Beaulieu A, Robert-Roth A, Romas-Remus C, Rovensky J, Alecock E, et al. Effect of interleukin-6 receptor inhibitor with tocilizumab in patients with rheumatoid arthritis: a double blind, placebo controlled randomised trial. Lancet, 2008; 371: 987-97. 
30. Shanahan JC, Moreland LW, Carter RH. Upcoming biologic agents for the treatment of rheumatic diseases. Curr opin Rheumatol 2003; 15: 226-36.

31. Lee JH, Slifman NR, Gershon SK, Edwards ET, Schwieterman WD, Siegel JN et al. Life threatening histoplasmosis complicating immunotherapy with tumour necrosis factor alpha antagonists infliximab and etanercept. Arthritis Rheum 2002; 46: 2565-70.

32. Ekstrom K, Hjalgrim H, Brandt L, Baecklund E, Klareskog L, Ekbom A, et al. Risk of malignant lymphoma in patients with rheumatoid arthritis and in their first degree relatives. Arthritis rheum 2003; 48: 963-70.

33. Mohan N, Edwards ET, Cupps TR, oliversio PJ, Sandberg G, Crayton $\mathrm{H}$ et al. Demyelination occurring during anti-tumour necrosis factor alpha therapy for inflammatory arthritis. Arthritis rheum 2001; 44: 2862-9.
34. Devos SA, Van Den Bossche N, De Vos M, Nacyaert JM. Adverse skin reactions to anti-TNF- alpha monoclonal antibody therapy. Dermatology 2003; 206 : 388-90.

35. Vidal F, Fontova R, Richart C. Severe neutropenia and thrombocytopenia associated with infliximab. Ann Int Med 2003; 139: 61-63.

36. Hochberg MC, Lebwohl MG, Plevy SE, Hobbs KF, Yocum DE. The benefit/ risk profile of TNF- blocking agents: findings of a consensus panel. Semin Arthritis Rheum, 2005; 34: 81936.

37. Day R. Adverse reactions to TNF-alpha inhibitors in rheumatoid arthritis. Lancet 2002; 359: 540-41.

38. Fan PT, Leong KH. The use of Biological agents in the treatment of rheumatoid arthritis. Ann Acad Med, Singapore 2007; 36: 128-34. 